(использовано 104 раза), стратегия реальности (240 раз), иерархия критериев (189 раз), и контрпример (357 раз). Применение рассматриваемых внушений во время гипнотического воздействия на сеансах гипнотерапии индуцирует углубление транса и, соответственно, осуществление эффективной коррекции ограничивающих верований. Перспективы дальнейших исследований усматриваются в разностороннем изучении лингвальных механизмов осуществления гипнотического воздействия на реципиента на материале китайского и английского языков.

Ключевые слова: гипнотический дискурс, гипностилистические шаблоны, верования, внушения.

Maksym Yu. KARPENKO,

PhD in Linguistics, Associate Professor at the Department of English Grammar, Odessa I. I. Mechnikov National University; 2 Dvoryanska Str., Odessa, 65082, Ukraine; tel.: +38 063 6662222; e-mail: m.yu.karpenko@gmail.com; ORCID ID:0000-0003-0308-5284

\title{
HYPNOSTYLISTIC PATTERNS OF SUGGESTION IN HYPNOTIC DISCOURSE
}

Summary. The article investigates hypnotic discourse, i.e. the result of communication in a situation of hypnotherapeutic influence together with all (tangible and intangible) constituents of the communicative situation. When applying hypnosis, the hypnotherapist uses hypnotic speech, which is characterized by specific hypnostylistic patterns. The purpose of this article is to outline the linguistic features of the functioning of hypnostylistic suggestions in Chinese hypnotic discourse. The object of the study is hypnotic discourse in Chinese, and the subject is the mechanisms of hypnotic communicative act in Chinese. The material is transcripts of speech recordings of hypnotherapists during hypnotic sessions in Chinese with a total volume of 50 hours. The following methods were used in the study: general scientific methods (induction and deduction, analysis and synthesis, quantitative, etc.) to derive scientifically sound inferences; general linguistic methods (discourse analysis) for the analysis of the lingual components of hypnotic discourse; the author 's technique of hypnostylistic analysis is used to single out lingual patterns of hypnotic impact and suggestion. The main results of the study. A frequent group of linguistic patterns that lead to a change in beliefs are those that are based on changing the size of the perception frame. These include: decrease and increase (213 cases of decrease and 338 cases of increase were registered), scaling (used 130 times) and metaframe (used 73 times). Also, one of the groups of suggestions that lead to a change of beliefs are those that are axiological in nature, they include: self-application (used 104 times), reality strategy (used 240 times), hierarchy of criteria (used 189 times), and counterexample (used 357 times). The use of the analyzed suggestions during the hypnotic effect of a hypnotherapy session makes it possible to deepen the trance and, accordingly, to effectively correct the restrictive beliefs. Prospects for further research are seen in the comprehensive study of the linguistic mechanisms of hypnotic effects on the recipient on the material of Chinese and English.

Key words: hypnotic discourse, hypnostylistic patterns, beliefs, suggestion.

Статтю отримано 5.10.2020 р.

https://doi.org/10.18524/2307-4558.2020.34.219517

УДК 811.161.1'373.2'374.73:168.522(477.74-25)

\section{МАЛЬЦЕВА Ольга Вадимовна,}

кандидат филологических наук, доцент кафедры общего и славянского языкознания Одесского национального университета имени И. И. Мечникова; Французский бульвар, 24/26, г. Одесса, 65058, Украина;

тел.: +38(048)7465697; e-mail: lorrizzy@gmail.com; ORCID ID: 0000-0002-3326-6812; SPIN: 8724-4410

\section{ГУЩИНА Юлианна Александровна,}

магистрант кафедры общего и славянского языкознания Одесского национального университета имени И. И. Мечникова; Французский бульвар, 24/26, г. Одесса, 65058, Украина; тел.: +38(048)7465697; e-mail: yulianna808@ukr.net; ORCID ID: 0000-0001-9243-3433

\section{ЛИНГВОКУЛЬТУРОЛОГИЧЕСКАЯ ХАРАКТЕРИСТИКА ОДЕССКИХ ЭРГОНИМОВ}

\footnotetext{
Аннотация. Цель статьи - анализ одесской эргонимии и отражения в ней региональной картины мира. Объектом анализа послужили эргонимы г. Одессы. Предмет исследования - лингвокультурологические процессы функционирования системы эргонимов г. Одессы. В работе использованы описательный метод и методы семантического, прагматического и когнитивного анализа. Результат исследования - эргонимы г. Одессы, будучи в основном историзмами, являются своеобразными маркерами определённых периодов в одесской городской истории и культуре. Материал статьи может быть использован при дальнейших сопоставительных изысканиях и построении типологии эргонимии. Выводы. В лексике каждого языка имена собственные образуют особый разряд, который противопоставляется именам нарицательным и обладает своими специфическими признаками. Исследование эргонимов тесно связано с изучением динамических процессов, происходящих в русской лексике на определённом временном срезе. В эргонимах присутствуют яркие следы традиций, поверий, мировоззрения, образной системы, концептов русского, греческого, арабского, еврейского и др. народов. Важно отметить, что они образуются по различным моделям, в реализации которых
} 
участвуют лексические средства, разнообразные с точки зрения их происхождения, апелляции к смежным разрядам имён собственных, к различным лексическо-тематическим группам, к различным пластам национально-культурного сознания, которое фиксируется и формируется благодаря фольклору, мифологии, литературе и т. д. Единицы, составляющие каждую лексико-семантическую группу, отличаются друг от друга не только семантически, но и сферой самостоятельного функционирования. Репрезентантами национально-языковой картины мира в одесских эргонимах выступают различные виды прецедентных имён и текстов, их число значительно больше примеров национально-маркированной лексики. Эффективность эргонима зависит от степени его соответствия картине мира и ценностных ориентиров потенциального покупателя. Это условие полностью выполняется в названиях, отражающих особенности определённого региона.

Ключевые слова: лексикология, ономастика, эргонимия, одесские эргонимы, русская городская речь, региональное койне, имя собственное.

Постановка проблемы. Наименования промышленных, торговых и развлекательных предприятий г. Одессы, будучи типичными эргонимами и обладая большим лингвокультурологическим потенциалом, до сих пор ещё не подвергались специальному комплексному изучению. Количество эргонимов постоянно увеличивается, что обусловлено количественным ростом разного рода предприятий и организаций (деловых объединений людей, объектов коммерции, культуры, спортивных заведений и т. д.).

Постановка задач исследования. Изучение одесских эргонимов как отдельной микросистемы, отличающейся спецификой синтагматических, парадигматических отношений, определённым набором типизированных словообразовательных моделей имеет мощный потенциал, так как здесь открываются перспективы для дальнейшего изучения эргонимов в лексикологии, социолингвистике и лингвокультурологии. Цель статьи - анализ одесской эргонимии и отражения в ней национальноязыковой картины мира. Предмет исследования - лингвокультурологические процессы фоункционирования системы эргонимов г. Одессы.

Связь с предыдущими и смежными исследованиями. Сегодня имена собственные интересуют представителей самых разнообразных наук. Однако в первую очередь собственные имена пристально исследуются лингвистами, поскольку любое наименование вне зависимости от того к какому объекту живой или неживой природы относится это слово (к человеку, животному, звездам, улице, городу, селу, реке, книге или коммерческой фирме), входящее в систему языка, образующееся по законам языка, живущее по определенным законам и употребляющееся в речи.

Авторы некоторых работ, в частности Е. В. Ворошилова [1], А. А. Трапезникова [4], Н. В. Шимкевич [5] затрагивают вопросы отражения в эргонимии языковой картины мира, однако отдельных исследований, посвященных этой проблеме, еще нет, что и послужило причиной обращения к анализу эргонимов в данном аспекте.

Это чрезвычайно сложное явление, изучение которого требует своих методов исследования, а также использования данных других наук - лексикологии, стилистики, истории языка и т. д.

Изложение основного материала. Выделение специальных ономастических проблем из общего круга лингвистических оправдывается положением имен собственных в языке.

(Собственные имена - часть языка, демонстрирующая наиболее парадоксальные ситуации, анализ которых должен способствовать возникновению новых, более углубленных лингвистических концепций» [3, с. 15]. В зависимости от объектов номинации все собственные имена можно разделить на определенные классы:

1. Антропонимы - собственные имена людей.

2. Топонимы - название различных географических объектов.

3. Теонимы - наименования божеств в политеистических религиях.

4. Прагматонимы - собственные имена, имеющие денотаты в практической деятельности человека и т. д.

Каждый класс имеет свою собственную систему элементов, которые находятся в особых взаимосвязях. Один из подклассов онимов - топонимы — образует внутри себя большой класс, называемый урбанонимами, которые, в свою очередь, делятся на такие виды:

1. Агоронимы - вид урбанонима - топоним для обозначения названий площадей и других открытых пространств в городах.

2. Годонимы - вид урбанонима - топоним для обозначения названий улиц.

3. Эргонимы - вид урбанонима - топоним для обозначения объединения людей, в том числе союзов, организаций, учреждений, корпораций, предприятий, заведений. В рамках исследования нас интересует именно этот вид урбанонимов.

Наложение имеющихся в научной литературе классификаций культурно-маркированной лексики на современное одесское эргонимное пространство русского языка позволило выделить ряд тематических групп культурно-маркированных слов, возведенных в ранг эргонимов или включённых в структуру составных наименований.

1. Этнографическая группа:

- Предметы быта (универсам «Авосъка», кафе «Лареи», ломбард «Сундук», торговый иентр "Сундук», универсам, а также магазин иветов "Лукошко»); 
- Наименования еды, включающие виды продуктов (лагазин-nекарня «Плюшка», пекарни: «Каравай», "Ватрушка», "Круассан»), начиональные блюда (кафе «Наш блинок», кафе "У тещии на блинах»);

- Названия предметов одежды и обуви (салон красоты «Сарафбан», магазин детской и подростковой обуви «Золотой башмачок», магазин женской одеждъ и обуви «Золотая туфелька»);

- Наименования жилищ (студия дизайна и текстиля «Терем», частный детский сад «Теремож», агенство недвижимости «Хата», магазин «Пряная хата», медичинский иентр "Дом», жилой комплекс «Аркадийский дворещ»).

2. Географическая группа:

- Наименования объектов физической географии, называющие определённый топообъект (mopговый иентр «Европа», ресторан «Елисейские поля», жилой колплекс «Париж», кинотеатр «Москва», ресторан-бар "Хеврон», кафе «Санторини», караоке-ресторан израильской кухни «Алленби», ресторан греческой кухни «Эллиникон»);

- Наименования объектов фозической географии, указывающие на конкретный фокт истории (торгово-монтажная фирма «Бородино»).

3. Группа общественно-политических реалий:

- Наименования объединений людей, в частности, по сословному признаку (центр выдачи сертификатов «Гильдия», сеть магазинов товаров для виноделия «Каста виноделов», ювелирный магазин «Кіаста»);

- Названия общественных заведений (кафе «Трактир», ресторан «Трактир на Греческой», арт-кофейня "Галерея», арт-кафе «КИНО»);

- Наименования торговых предприятий (в эргонимах это составные названия со стержневым компонентом "лавка) ("Ковровая лавка», "Мебельная лавка», "Ювелирная лавка», сеть минимаркетов «Лавка») и онимы, созданные по типу устойчивого словосочетания (гостиный двор» (отель, банкетный зал, сеть магазинов «Гостиный двор», жилой комплекс «Одесский двор», торговая бирла «Кобейный двор», автомойка «Каретный двор»);

- Названия денежных единиц (суперларкет и аптека «Копейка», пивной клуб «Золотая монета», сеть денежных переводов "Быстрая копейка», студия красоты "Франк», магазин табака и курительных принадлежностей «Песо»).

4. Әргонимы - прецедентные тексты:

- названия произведений художественной литературы (магазин «Алиса в Зазеркалье», рестораны "Дворянское гнездо», "Гамбринус», кафе "Три толстяка», автомойка и квест-комната «Сияние»);

- отрывки из художественных текстов (пансионат «У лукоморъя»);

- названия фольклорных текстов и устойчивые выражения из них (детский магазин «Колобож», ресторан «Гуси-лебеди», детский центр «Теремож»);

- названия детских мультфильмов или их фрагменты (зоомагазин «Кошкин дом», детский магазин «Антошка», магазин игрушек «з8 попугаев»);

- названия культовых фольмов (ресторан «Кавказская пленница», агентство домашнего персонала «По семейныл обстоятельствам», спортзал «Терминатор», монтажная фбирла «Годзилла», ветеринарный чентр «Хатико»);

- названия телевизионных передач (турбирла «Вокруг света»);

- строки из популярных песен (ресторан «Калинка-малинка», турбирла «За иетыре моря», магазин бижутерии «Мадам Брошкина»);

- устойчивые выражения (турбирла «Лицол кличу», кафе-бар «ёлки-палки», магазин «Белая ворона», супермаркет "Два шага»);

- этикетные формулы, пожелания (оздоровительный комплекс «C легким паром», турбирла «Скатертъю дорога», бито-аптека «Будъ здоров»).

5. Әргонимы - прецедентные имена:

Прецедентное имя - это (индивидуальное имя, связанное или с широко известным текстом, относящимся к числу прецедентных, или с ситуацией, широко известной носителям языка и выступающей как прецедентная, имя-символ, указывающее на некоторую эталонную совокупность определённых качеств» [2, с. 149]. Здесь мы выделяем:

- имена исторических лиц (рестораны «Бабель Фиш», "Давыдов», кафбе "Мишка Япониик», гостинича «Колумб», кафе "Гоголь у моря», иентр развития «Монтессори», театр таниа «Яворская», торгово-строительная фирма "Овидий», кафе-бар "Уточкино», клуб «Морган»);

- имена героев литературных произведений (салон моды «Ассоль», ветеринарная аптека "Айболит», сеть магазинов строительных материалов «Вакула», зоомагазин «Базилио», кондитерский иее «Буратино», сеть билетных иентров «Карабас»);

- имена героев художественных фрильмов (ресторан «Милино», служба такси и доставки едь «Бонд», битнес-клуб “Халю», битнес-иентр "Магнетто», торговая компания «Тор», сервисная служба по прочистке канализачии «Бэтмен», сервисный чентр «Электроник», бильярдный клуб «Арамис»); 
- имена мифологических персонажей (салон красоты «Селена», студия таниа «Эридан», торгово-строительная компания «Гермес»; агенство безопасности, сеть ювелирньх магазинов, торгово-технический уентр, магазин обуви - «Зевс»; ателье-студия "Макошь», салон красоты «Афродита»).

Выводы. Эргонимы могут выступать своеобразными (возбудителями» интереса к тому или иному факту культуры / истории (чаще всего не хрестоматийному, а малоизвестному) и как бы подталкивать посетителей / покупателей к стремлению их расшифрровать (перечитать текст, ещё раз посмотреть фильм и т. д.), следовательно, в какой-то степени они выполняют и общеобразовательную функцию. Их содержание и восприятие подвергаются влиянию географических, климатических, исторических, религиозных, культурных фокторов.

Значительный ассоциативный фон наиболее известных топонимов (Mосква, Kuев, Oдесса, Eвро$n a$ и пр.) также широко используется в эргонимии, повышая, по замыслу номинаторов, престиж, репутацию именуемого предприятия. Это можно объяснить их яркой образностью, эмоциональностью, что очень важно для эргонимов, т. к. они призваны привлечь внимание к тому или иному объекту, предприятию, стать его рекламой, (визитной карточкой).

\section{Литература}

1. Ворошилова Е. В. Ономастикон города Канска как отражение истории и культуры народа : автореф. дисс. канд. филол. наук : 10.02.01. Тюмень, 2007. $19 \mathrm{c.}$

2. Гудков Д. Б. Теория и практика межкультурной коммуникации. Москва : Гнозис, 2003. 288 с.

3. Степанов Є. М. Мова міста як соціолінгвістична проблема. Вісник Львівського ун-ту. Сер. філологічна. Львів : Львівський національний університет ім. І. Франка, 2006. Вип. 38. Ч. II. С. 65-71.

4. Степанов Е. Н. Взаимодействие научных лингвистических подходов в исследовании русской городской речи. Мова : науково-теоретичний часопис з мовознавства. Одеса : Астропринт, 2014. № 21. С. 27 -35.

5. Суперанская А. В. Эволюция теории имени собственного в Европе. Вопросы фбилологии. Москва : Ин-т языкознания РАН, 2002. № 3 (12). С. 5-17.

6. Трапезникова А. А. Ономастическое сознание современного горожанина: на материале эргонимии Красноярска : автореф. дисс. канд. филол. наук : 10.02.01. Красноярск, 2010. 21 с.

7. Шимкевич Н. В. Русская коммерческая эргонимия: прагматический и лингвокультурологический аспекты : автореф. дис. канд. филол. наук : 10.02.01. Екатеринбург, 2002. 22 с.

\section{References}

1. Voroshilova E. V. (2007). Onomasticon of the city of Kansk as a reflection of the history and culture of the people: Author's thesis. [Onomastikon goroda Kanska kak otrazheniye istorii i kul'tury naroda : avtoref. diss. kand. filol. nauk : 10.02.01]. Tyumen, $19 \mathrm{p}$.

2. Gudkov D. B. (2003). Theory and practice of intercultural communication [Teoriya i praktika mezhkul'turnoy kommunikatsii]. Gnosis. Moscow. 288 p.

3. Stepanov, Ie. (2006), "Language of city as a sociolinguistic problem", Visnyk of L'viv University, Series philological ["Mova mista iak sotsiolinhvistychna problema", Visnyk L'vivs'koho universytetu, Seriia filolohichna], Lviv Ivan Franko National University Press, vol. 38, part II, pp. 65-71.

4. Stepanov, Ie. N. (2014), "Interaction of scientific linguistic approaches to research the Russian urban language", Mova / Language ["Vzaimodeystviye nauchnykh lingvisticheskikh podkhodov v issledovanii russkoy gorodskoy rechi", Mova], Odessa I. I. Mechnikov National University, Astroprint Publishing house, Odessa, vol. 21, pp. $27-35$.

5. Superanskaya A. V. (2002). "Evolution of the proper name theory in Europe", Voprosy filologii ["Evolyutsiya teorii imeni sobstvennogo v Yevrope", Voprosy filologii], Institute of Linguistics of the RAS, Moscow, issue 3, pp. 5-17.

6. Trapeznikova A. A. (2010), Onomastic consciousness of a modern city dweller: on the material of Krasnoyarsk ergonymy: Author's thesis. [Onomasticheskoye soznaniye sovremennogo gorozhanina : na materiale ergonimii Krasnoyarska : avtoref. dis. ... kand. filol. nauk : 10.02.01], Krasnoyarsk, $21 \mathrm{p}$.

7. Shimkevich, N. V. (2002), Russian commercial ergonymy : pragmatic and linguoculturological aspects: Author's thesis. [Russkaya kommercheskaya ergonimiya : pragmaticheskiy i lingvokul'turologicheskiy aspekty : avtoref. dis. kand. filol. nauk: 10.02.01], Yekaterinburg, $22 \mathrm{p}$. 
МАЛЬЦЕВА Ольга Вадимівна,

кандидат філологічних наук, доцент кафедри загального і слов'янського мовознавства Одеського національного університету імені I. I. Мечникова; Французький бульвар, 24/26, м. Одеса, 65058, Україна;

тел.: +38(048)7465697; e-mail: lorrizzy@gmail.com; ORCID ID: 0000-0002-3326-6812; SPIN: 8724-4410

\section{ГУЩИНА Юліанна Олександрівна,}

магістрант кафедри загального та слов'янського мовознавства Одеського національного університету

імені I. I. Мечникова; Французький бульвар, 24/26, м. Одеса, 65058, Україна; тел.: + 38(048)7465697;

e-mail: yulianna808@ukr.net; ORCID ID: 0000-0001-9243-3433

\section{ЛІНГВОКУЛЬТУРОЛОГІЧНА ХАРАКТЕРИСТИКА ОДЕСЬКИХ ЕРГОНІМІВ}

Анотація. Мета статті - аналіз одеської ергонімії та відображення в ній регіональної картини світу. Об’єктом аналізу послужили ергоніми м. Одеси. Предмет дослідження - лінгвокультурологічні процеси функціонування системи ергонімів м. Одеси. У роботі використано описовий метод і методи семантичного, прагматичного та когнітивного аналізу. Результат дослідження - ергоніми м. Одеси як, здебільшого, історизми, є своєрідними маркерами певних періодів одеської міської історії та культури. Матеріал статті може бути використаний у подальших дослідженнях і у творенні типології ергонімії. Висновки. У лексиці кожної мови власні імена утворюють особливий розряд, що протиставлений іменам загальним, маючи свої специфічні ознаки. Дослідження ергонімії тісно пов'язане з вивченням динамічних процесів, що відбуваються в російській лексиці на певному часовому зрізі. В ергонімії наявні яскраві сліди традицій, повір'їв, світогляду, образної системи, концептів російського, українського, грецького, арабського, єврейського та ін. народів. Важливо відзначити, що вони утворюються за різними моделями, в реалізації яких беруть участь лексичні засоби, різноманітні з точки зору їх походження, апеляції до суміжних розрядів власних назв, до різних лексико-тематичних груп, до різних шарів національно-культурної свідомості, яка фіксується і формується завдяки фольклору, міфології, літературі тощо. Одиниці, що становлять кожну лексико-семантичну групу, відрізняються одна від іншої не тільки семантично, а й сферою самостійного функціонування. Репрезентантами національно-мовної картини світу в системі одеських ергонімів виступають різні види прецедентних імен і текстів; їх кількість значно більша за кількість прикладів національно-маркованої лексики. Ефективність ергоніма залежить від ступеня його відповідності картині світу і іннісних орієнтирів потенційного покупця. Ця умова повністю виконується в назвах, що відображають особливості певного регіону.

Ключові слова: лексикологія, ономастика, ергонімія, одеські ергоніми, російське міське мовлення, регіональне койне, власне ім'я.

Olga V. MALTSEVA,

Candidate of Philology, Associate Professor of the Department of General and Slavic Linguistics, Odessa I. I. Mechnikov National University; 24/26 Frantsuzsky blvd., Odessa, 65058, Ukraine; tel.: +38(048)7465697; e-mail: lorrizzy@gmail.com; ORCID ID: 0000-0002-3326-6812; SPIN: 8724-4410

\section{Yulianna A. GUSHCHINA,}

Master's student of the Department of General and Slavic Linguistics, Odessa I. I. Mechnikov National University; 24/26 Frantsuzsky blvd., Odessa, 65058, Ukraine; tel.: +38(048)7465697; e-mail: yulianna808@ukr.net; ORCID ID: 0000-0001-9243-3433

\section{LINGUOCULTUROLOGICAL CHARACTERISTICS OF ODESSA' ERGONYMS}

Summary. The purpose of the article is to analyze Odessa ergonymy and its reflection of the national and linguistic picture of the world. The object of the analysis was the ergonyms of Odessa. The subject of the research is the linguoculturological processes of the appearance and development of ergonyms in Odessa. Descriptive method and methods of semantic, cognitive and pragmatic analysis were used in the work. The result of the research is that the ergonyms of the city of Odessa, being basically historicisms, are a kind of markers of certain periods in Odessa history and culture. The material of the article can be used for further comparative research and the construction of a typology of ergonymy. Conclusions. In the vocabulary of each language, proper names form a special category, which is opposed to common nouns and has its own specific characteristics. The study of ergonyms is closely related to the study of the dynamic processes occurring in Russian vocabulary at a certain time frame. Ergonyms contain vivid traces of traditions, beliefs, worldview, figurative system, concepts of Russian, Greek, Arab, Jewish and other peoples. It is important to note that they are formed according to various models, in the implementation of which lexical means, various in terms of their origin, are involved, appeals to adjacent categories of proper names, to various lexical and thematic groups, to various layers of national and cultural consciousness, which is fixed and formed thanks to folklore, mythology, literature, etc. The units that make up each lexico-semantic group differ from each other not only semantically, but also in the sphere of independent functioning. Representatives of the national and linguistic picture of the world in Odessa ergonyms are various types of precedent names and texts, their number is much larger than examples of nationally marked vocabulary. The effectiveness of an ergonym depends on the degree to which it corresponds to the picture of the world and the values of the potential buyer. This condition is fully met in the names reflecting the characteristics of a particular region.

Key words: lexicology, onomastics, ergonymy, linguoculturology, Odessa ergonyms, the Russian urban speech, regional koine, proper name. 